\title{
Coloquio «De la emigración a la inmigración en Europa»
}

\section{Encuentro del Grupo de Investigaciones sobre Migraciones ISA, Cerisy-la-Salle, 2-6 de junio de 2005}

Graciela Sarrible

Universitat de Barcelona

Es habitual que los grupos de investigaciones realicen encuentros entre sus miembros y que acepten a todos aquellos de otros grupos que quieran asistir y estén trabajando sobre los temas que se van a presentar. El encuentro sobre migración reunió, sorprendentemente, a pocas personas ajenas a este grupo y a pocas, también, ajenas a la sociología. Normalmente, la diversidad es corriente, pero en este caso fue excepcional.

Las dos intervenciones iniciales estuvieron destinadas a hacer un balance o a sugerir nuevos rumbos o señalar deficiencias. En primer lugar, Stephen Castles (director del Centre of Refugee Studies, Universidad de Oxford, Gran Bretaña) realizó una intervención señalando las deficiencias no tanto de los investigadores allí presentes, ni de los temas que habitualmente tratan, sino de la sociología en general, en esa búsqueda desesperada de leyes universales en vez de considerar la diversidad de situaciones y atender, incluso con teorías de menor alcance, la heterogeneidad de la realidad que intentamos discernir. En segundo lugar, Robin Cohen (profesor de Sociología e investigador del Centre for the Study of Globalization and Regionalization, Universidad de Warwick, Gran Bretaña), muy al uso de las tendencias a los cuestionamientos éticos de la actualidad, insistió en las dimensiones del derecho y en una apertura muy lejos de lo que políticamente marcan como línea los países que ahora reciben contingentes migratorios y están en el centro. Su propuesta, decididamente maniqueísta, de distinguir entre migrantes buenos y migrantes malos nos remite al trato que reciben las personas de distintos orígenes en España o a las posibilidades reales que tienen de obtener contratos en su país de origen.

He percibido, como una forma de ver o sentir lo que está sucediendo, que existe un viraje de los investigadores naturales o nativos de los grandes centros de investigación, en esos países, hacia otros, de la periferia, que pueden o no estar en los mismos u otros centros de investigación. La ventaja de estos encuentros es que son todo lo democráticos que pueden ser dentro de estructuras con jerarquías. La atención no es la misma, pero todos los asistentes tienen derecho a hablar y a exponer sus puntos de vista, así como a criticar los trabajos que exponen sus colegas. 
En este viraje, no sólo hay un cambio en el origen (no necesariamente en la nacionalidad) de los exponentes, sino sobre todo en la óptica con que se enfoca a las personas que migran, fundamentalmente de los países periféricos hacia los países centrales. La situación se dio hace unos años y se vio sobre todo en las mesas dedicadas eufemísticamente a "amor y sexo", que por suerte no sólo se centraban en la prostitución. Cambió desde la posición de víctima a otra más permisiva o comprensiva o no negativa. Adriana Piscitelli (Núcleo de Estudios de Género, UNICAMP, Saô Paulo, Brasil) explicó que las mujeres que han sido trabajadoras del sexo y que han sido invitadas a casarse por hombres que han conocido afirman que se trata de una estrategia. Más que amor, es una propuesta entendida en términos muy racionales, como habitualmente analizamos las relaciones de pareja a través de modelos económicos e incluso sociológicos. Las prostitutas del este en Turquía no se ven a sí mismas como tales. Los matrimonios mixtos en Suiza muestran dobles expectativas, no sólo por parte de las mujeres que van a residir en ese país, sino también por parte de los hombres que les piden que lo hagan.

Este cambio es muy importante porque, quizás, la necesidad del giro de lo negativo a lo positivo surge por cuestiones personales, fundamentalmente biográficas. Son las personas que tienen inscrita en su propia vida o en la de sus ascendientes una migración, que quieren que esa visión despectiva o al menos lastimosa se transforme en un motivo, a ser posible, de orgullo. Proponen abandonar, aunque no lo digan, las visiones paternalistas y sobre todo victimistas por propuestas de participación activa, de independencia y de reciprocidad.

El artículo de David Bartram (Department of Sociology, Universidad de Reading, Gran Bretaña), que propone estudiar las razones por las cuales no hay más trabajadores extranjeros en Finlandia, comparte este propósito de un giro de la situación: de los ejemplos que el autor estima como positivos, pasaríamos a los negativos, que muestran que no sucede lo mismo que en la mayoría de los otros países. Es cierto que normalmente estudiamos lo que sucede y no pensamos o no reflexionamos acerca de lo que no sucede.

Una visión interesante de la ocupación del espacio fue la que aportó Serge Weber (UFR des Sciences Géographiques, Universidad de Provence, Aix-enProvence, Francia) al analizar ciudades italianas y la proporción de extranjeros en cada uno de los distritos y lugares. Del discurso de lo que no pasa, se considera lo que está sucediendo y cómo, y las relaciones que se establecen entre esos grupos, al principio foráneos y después interrelacionándose con los actores locales. La sociología necesita de estudios espaciales, realizados a ser posible por especialistas, que le permitan completar sus propias visiones, a veces limitadas.

Hideki Tarumoto (Department of Sociology, Universidad de Hokkaido, Japón) explicó con varios gráficos la distancia que media entre personas sin papeles, residentes y ciudadanos. Con un gráfico concéntrico y después con otro de niveles, hizo referencia a las distancias que existen entre unos y otros y a las dificultades del paso de una categoría a otra. 
La mesa sobre las repúblicas transcaucásicas se prolongó, dado el interés de muchas de las personas presentes y de la novedad de estos estudios. Hasta hace poco resultaba difícil realizarlos y hoy despiertan mucho interés, ya que escapan al clásico esquema periferia-centro, que deja pensar, erróneamente, que son los únicos movimientos que se producen o las únicas direcciones que existen.

La mesa sobre la Europa del sur siempre se espera para decir si es distinta, para preguntar si tiene un modelo en el que todos participan, para resaltar los cambios de las últimas décadas. En este caso, las aportaciones fueron realmente diversas y no hubo superposiciones, ni encuentros, ni discontinuidad. Leonidas Papakonstantinidis (Centre for Development Studies, Grecia) explicó la forma de trabajo de las personas originarias de Polonia en el medio rural del sur del Peloponeso. Su propuesta de interpretación y sus modelos constituyeron un motivo de reflexión y de discusión, no sólo durante la sesión, donde siempre falta un poco de tiempo, sino después, durante el tiempo que quedaba fuera de las sesiones. El trabajo de Mauricio Ambrosini (Facoltà di Science della Formazione, Università degli Studi di Genova, Italia), sobre la aportación de las mujeres al trabajo doméstico y los cambios que ellas generan, recuerda, aunque sólo en algunos aspectos, algunas aportaciones sobre la sustitución que permiten estas mujeres a los locales con su ingreso en el mercado de trabajo. De Ambrosini destacó la nueva tendencia que se aprecia en algunos estudios de hablar de sentimientos. Ya lo había propuesto Weber, pero pocos le hicieron caso o se vieron marginados al considerarlo. Frente a la propuesta económica, estimó que la sociología puede empezar a considerar otras opciones que no siempre son valores y que pueden ser sentimientos. Martin Geiger (Eurofor, Universidad de Bonn, Alemania) y yo misma hablamos de España. Geiger presentó un trabajo realmente crítico sobre la política de migración, considerando la situación de los actores sociales y los inmigrantes marroquíes en Almería. Su exposición no decepcionó. No todo está dicho. Faltan, sobre todo, visiones críticas que lancen propuestas para mejorar las salidas concretas que a partir de ahora hay que empezar a gestionar en el ámbito de lo que se llama integración.

Y ésta fue una de las discusiones centrales de todo el encuentro. Danièle Juteau (profesora del Department of Sociology, Universidad de Montreal, Canadá), del Grupo de Investigación de Relaciones Interétnicas, se interesó por el mundo académico y su opinión sobre el término «integración» en los distintos países. A pesar de la diversidad de respuestas, no llegó a haber diferencias sustanciales, sino opciones diversas. En mi caso, contesté que estimaba que la falta de acuerdo académico sobre la adopción o no de este concepto podía provenir de la falta de convergencia con la idea que los políticos tienen de la integración, más como exigencia que como proceso, y de la otra exigencia, la de la opinión pública, que se acercaría más a la idea de asimilación o parecerse a los locales.

Otros explicaron por qué seguían usando ese concepto, aunque le dieran otro significado. Otros prefirieron el término «inclusión», que tan en boga ha esta- 
do en los trabajos europeos. En mi caso, prefiero indicadores de participación, aunque la noción esté lejos de lo que se pide o exige como integración. En el siguiente panel el debate continuó. Evidentemente, mencionar la cohesión social y la cohabitación de personas diversas exige hablar de cómo se llevan, de sus derechos o de las políticas que los distinguen. En este caso, Ellie Vasta (profesora de Estudios Étnicos, Programme on Integration and Social Change, Universidad de Oxford, Gran Bretaña), que coordinaba el panel, se mostró partidaria del término, de rescatarlo y de definirlo, de tener en cuenta la solidaridad, pero no de abandonarlo como gastado. Muchos participantes mostraron su aceptación del término, que todavía no está perimido, como algunos desearían.

La mesa sobre la migración México-EEUU (Gustavo Verduzco, Francisco Alba, Silvia Giorguli y Manuel Ángel Castillo, miembros del Colegio de México, México) estuvo formada por primera vez exclusivamente por interlocutores mexicanos, que dieron una visión interesante y complementaria. El paralelismo de la situación de Europa con México como tierra de paso, pero también como asentamiento de otras comunidades que vienen del sur, no sólo fue interesante, sino también nuevo y distinto. Es un análisis que hay que considerar, con calma, como una aportación a un debate que a veces está gastado por lo reiterativo de los discursos.

La última de las sesiones fue aquella con la que comencé el informe del congreso: prostitución, pero también amor y sexo. Las visiones alternativas a las que se daban hace unos años contribuyeron a un cambio radical de posturas y a una reivindicación, relativamente positiva o por lo menos no condenatoria, de la vida y los quehaceres de estas personas.

Como balance final, quisiera destacar, en términos generales y sin hacer mención a ninguna aportación en particular, lo que me parece un defecto o una desviación de la sociología, en general, y no precisamente de los estudios de migración. Nos estamos alejando de las mediciones. Claro que están bien los estudios cualitativos, pero no son suficientes. Creo que hemos perdido de vista para qué pueden utilizarse. El mayor peligro, que muchas veces se concreta, es el de las generalizaciones. ¿Cómo podemos extender el estudio de contados casos a la población general? ¿Cómo podemos decir que la generalización es correcta? ¿Cómo podemos estimar que existe representatividad?

Los estudios cuantitativos no deberían desterrarse. Deberían ser el paso inicial o un fin en sí mismos en muchos casos. No se puede partir del estudio de unos casos o de la realización de unas entrevistas en profundidad para llegar a la universalización de lo que se ha visto o constatado. Así llegamos a las generalizaciones excesivas, que muestran una sociedad que no existe, porque en realidad se refieren a minorías o grupos marginales. Eso fue lo que me sucedió cuando intervine en el mismo grupo de investigación en una anterior reunión en Nueva York. Mientras se hablaba de mujeres violadas, víctimas o prostitutas, yo me refería a trabajadoras que migraban solas y eran autónomas. La persona que presidía la mesa deseó un debate en profundidad e impulsó a todas las que habían descrito un panorama tan negro a responderme. No había res- 
puesta posible. Yo hablaba de la mayoría y ellas, de excepciones. Pero no lo habían dicho.

Hagamos de la sociología una disciplina creíble. Los debates sirven para poner las cosas en su lugar. Las historias personales pueden ser divertidas como un libro, pero debemos cernir el lugar que realmente ocupan en la realidad. En encuentros como éste siempre se aprende, pero estoy segura de que no todos hacemos el mismo balance. Yo por lo menos aprendí mucho. 